\title{
Curcumin protects renal tubular epithelial cells from high glucose-induced epithelial-to-mesenchymal transition through Nrf2-mediated upregulation of heme oxygenase-1
}

\author{
XIULI ZHANG ${ }^{1-3}$, DAN LIANG $^{4}$, LIN GUO $^{5}$, WEI LIANG ${ }^{1}$, YAN JIANG $^{1}$, \\ HONGJUAN $\mathrm{LI}^{4}$, YUE ZHAO ${ }^{2}$, SHUMIN LU ${ }^{1}$ and ZHI-HONG $\mathrm{CHI}^{3}$ \\ ${ }^{1}$ Department of Nephrology, Benxi Center Hospital, China Medical University, Benxi, Liaoning 117000; \\ ${ }^{2}$ Key Laboratory of Medical Cell Biology, Ministry of Education; ${ }^{3}$ Department of Pathophysiology, \\ China Medical University, Shenyang, Liaoning 110001; ${ }^{4}$ Troops of 95935 Unit; \\ ${ }^{5}$ Troops of 93253 Unit, Harbin, Heilongjiang 150111, P.R. China
}

Received February 13, 2014; Accepted March 9, 2015

DOI: $10.3892 / \mathrm{mmr} .2015 .3556$

\begin{abstract}
Curcumin has been observed to exhibit an anti-fibrotic effect in the liver, lung and gallbladder. However, the mechanisms underlying the cytoprotective effects of curcumin remain to be elucidated. The epithelial-to-mesenchymal transition (EMT) of mature tubular epithelial cells in the kidney is considered to contribute to the renal accumulation of matrix proteins associated with diabetic nephropathy. The EMT is also closely associated with the progression of renal interstitial fibrosis and oxidative stress. This process may occur through abrogation of high glucose (HG)-induced oxidative stress via activation of nuclear factor (erythroid-derived 2)-like 2 (Nrf2) and heme oxygenase-1 (HO-1) in kidney tubular epithelial cells. In the present study, the effect of curcumin on HG-induced EMT in the NRK-52E normal rat kidney tubular epithelial cell line was investigated, and whether the effect of curcumin was mediated by the induction of Nrf2 and HO-1 expression was examined. The present study revealed that curcumin was able to prevent events associated with EMT, including the downregulation of E-cadherin and the increased expression of $\alpha$-smooth muscle
\end{abstract}

Correspondence to: Dr Xiuli Zhang, Department of Nephrology, Benxi Center Hospital, China Medical University, 29 Victory Road, Benxi, Liaoning 117000, P.R. China

E-mail: zhang2013_11@163.com

Abbreviations: NRK-52E cells, normal rat kidney tubular epithelial cells; EMT, epithelial-to-mesenchymal transition; HG, high glucose; DMEM, Dulbecco's modified Eagle's medium; SMA, smooth muscle actin; RIPA, radioimmunoprecipitation assay; TGF, transforming growth factor; TBS, Tris-buffered saline; Nrf2, nuclear factor (erythroid-derived 2)-like 2; HO-1, heme oxygenase-1; MTT, 3-(4,5-dimethylthiazol-2-y)-2,5-diphenyltetrazolium bromide

Key words: renal tubular epithelial cells, high glucose, curcumin, epithelial-to-mesenchymal transition, nuclear factor (erythroidderived 2)-like 2 actin. Further analysis revealed that the expression levels of Nrf2 and HO-1 protein were elevated to a greater extent in the curcumin pretreated NRK-52E cells compared with those of the control. Notably, knockdown of Nrf2 with small interfering RNA prevented the curcumin-induced elevation in expression of HO-1 and the associated anti-fibrotic effects. In conclusion, the present findings suggested that curcumin may be significant in cellular antioxidant defense, through the activation of $\mathrm{Nrf} 2$ and HO-1, thereby protecting the NRK-52E cells from HG-induced EMT.

\section{Introduction}

Diabetic nephropathy (DN) is the leading cause of chronic kidney failure and end-stage renal disease worldwide, and the prevalence of this disease has progressively increased $(1,2)$. DN is characterized pathologically by the progressive accumulation of extracellular matrix (ECM) proteins in the basement membranes, glomerular mesangium and the peritubular interstitium. DN may eventually lead to kidney scarring and ultimately nephron dropout $(3,4)$. Although glomerulosclerosis is a defining feature of DN, it is the extent of tubulointerstitial injury that fundamentally determines the rate of decline in renal function (5). Data have suggested that tubulointerstitial fibrosis also occurs at an early stage of diabetic renal injury and correlates closely with the decline in renal function observed in certain groups of patients (5-7). Accumulating evidence has implicated the epithelial-to-mesenchymal transition (EMT) of mature tubular epithelial cells in the kidney as a contributing factor to the renal accumulation of matrix proteins associated with DN. In addition, EMT is closely associated with the progression of renal interstitial fibrosis, which is characterized by a loss of the typical features of normal epithelial cells and a gain in the characteristics of ECM-producing myofibroblasts (8-10). Furthermore, blockade of certain stages involved in EMT significantly reduces the formation of fibrotic lesions in specific models of kidney fibrosis, suggesting that EMT may be significant in the development of nephropathy (11-13). 
It has been hypothesized that oxidative stress may contribute to the development of diabetic renal complications, including the EMT of tubular epithelial cells, which are observed in renal tissues even during the early stages of diabetes (14-16). As a key feature of the intracellular antioxidant machinery, nuclear factor (erythroid-derived 2)-like 2 (Nrf2) dissociates from its cytosolic inhibitor Kelch-like erythropore concentrating hormone-associated protein 1 (Keap1), translocates to the nucleus and regulates the coordinated induction of a number of genes, which encode numerous antioxidant and phase II detoxifying enzymes (17-19). One important Nrf2 target gene, heme oxygenase-1 (HO-1), is considered to be significant in the degradation of pro-oxidant heme, which results in the production of anti-inflammatory, antioxidant and anti-apoptotic metabolites $(20,21)$. The essential role of Nrf2 in combating oxidative stress has been demonstrated by investigations revealing the increased sensitivity of $\mathrm{Nrf}^{-/-}$mice to various types of insult, including high glucose $(\mathrm{HG})$-induced oxidative damage $(18,22)$. HO- 1 , which is induced by multiple transcription factors, including $\mathrm{Nrf} 2$, to protect the kidney from injury may aid in devising a therapeutic approach against the development of DN $(23,24)$. Previous studies have revealed that the increased expression of HO-1 is able to attenuate cytokine- and glucose-mediated cell growth arrest and apoptosis in vitro and in vivo (25). In addition, HO-1 deficiency has been demonstrated to be associated with increased fibrosis, increased tubular transforming growth factor (TGF)- $\beta 1$ expression, inflammation and enhanced EMT in obstructive kidney disease (26).

Curcumin (diferuloylmethane) is a commonly used flavoring and coloring agent, and is a major component of the yellow spice, turmeric, derived from the rhizomes of Curcuma longa (27). Curcumin exhibits a number of biological effects, including antioxidant, anti-inflammatory and wound-healing properties (28-31). In addition, previous studies have indicated that curcumin has anti-fibrotic effects in the liver and the lungs, providing relief from cystic fibrosis $(32,33)$. In immortalized rat kidney interstitial fibroblasts, curcumin has been observed to attenuate TGF- $\beta 1$-induced fibrosis through the downregulation of TGF- $\beta$ receptor II (34). In the unilateral ureteral obstruction (UUO) rat kidney fibrosis model, curcumin has been observed to inhibit inflammation and fibrosis of the renal interstitium by inhibition of the NF- $\mathrm{B}$-dependent signaling pathway (35). Furthermore, the antioxidant properties of curcumin have been observed to be effective in improving renal function in certain diabetic animal models $(36,37)$, as well as in acute kidney failure induced by ischemia-reperfusion (38). However, it remains to be elucidated whether pretreatment with curcumin in tubular epithelial cells leads to an increase in the Nrf2 protein level and alleviates the EMT of tubular epithelial cells. Emerging evidence has suggested that curcumin induces HO-1 mRNA and protein expression in the proximal tubule cells through transcriptional mechanisms and may also involve the $\mathrm{NF}-\kappa \mathrm{B}$ pathway (39) Notably, Gaedeke et al (40) demonstrated that curcumin treatment in nephritic animal models decreased fibrosis by inducing the expression of Nrf2 and HO-1. Therefore, it was hypothesized that administration of curcumin may increase the cellular antioxidant defense capacity via activation of Nrf2 and HO-1 expression, thereby protecting NRK-52E cells from the effects of HG-induced EMT.

\section{Materials and methods}

Cell culture. The NRK-52E normal rat kidney tubular epithelial cell line was purchased from the American Type Culture Collection (Manassas, VA, USA). The cells were cultured in a $5 \% \mathrm{CO}_{2}$ atmosphere in complete Dulbecco's modified Eagle's medium (DMEM; low glucose; Gibco Life Technologies, Grand Island, NY, USA), which contained $10 \%$ fetal bovine serum (Gibco Life Technologies), $4 \mathrm{mM}$ L-glutamine (Boster Biological Technology Ltd., Wuahn, China) and $1 \%$ penicillin/streptomycin (Sigma-Aldrich, St. Louis, MO, USA) at a density of $5 \times 10^{3}$ cells/well in six-well culture plates. Once the cells were almost confluent, they were transferred to serum-free DMEM for $24 \mathrm{~h}$ at $37^{\circ} \mathrm{C}$ to arrest and synchronize cell growth. In the control groups, the cells were treated with fresh serum-free DMEM only, which contained $5 \mathrm{mmol} / \mathrm{l}$ glucose. In the experimental groups, the cells were subjected to pretreatment with 5,10 or $20 \mu \mathrm{M}$ curcumin (Santa Cruz Biotechnology, Inc., Dallas, TX, USA) and then cultured for $24 \mathrm{~h}$ at $37^{\circ} \mathrm{C}$. Subsequently, the medium was changed and the cells were treated for an additional $48 \mathrm{~h}$ with $30 \mathrm{mM} \mathrm{HG}$ at $37^{\circ} \mathrm{C}$ (Boster Biological Technology Ltd.). The concentration of glucose was determined as previously described (12) and with reference to preliminary experiments by our group. In some experiments, the cells were treated wuth $0,5,10$ or $20 \mu \mathrm{M}$ curcumin for $24 \mathrm{~h}$, or $10 \mu \mathrm{M}$ curcumin for $0,3,6,12,24$ or $48 \mathrm{~h}$, and the expression levels of Nrf2 were detected by western blotting. Cells were also treated with $50 \mu \mathrm{M}$ tin protoporphyrin (SnPP), a known inhibitor of $\mathrm{HO}$, in order to study changes to $\mathrm{HO}$.

Experimental groups. The cells were divided into six groups, as follows: Control group, treated with serum-free DMEM; siRNA group, subjected to Nrf2-siRNA transfection; curcumin group, treated with $10 \mu \mathrm{M}$ curcumin for $24 \mathrm{~h}$; HG group, treated with $30 \mathrm{mM} \mathrm{HG}$ for $48 \mathrm{~h}$; HG/curcumin group, pretreated with $10 \mu \mathrm{M}$ curcumin for $24 \mathrm{~h}$, followed by $30 \mathrm{mM} \mathrm{HG}$ treatment for $48 \mathrm{~h}$; HG/curcumin/Nrf2-siRNA group, $24 \mathrm{~h}$ post-transfection the cells were treated with $10 \mu \mathrm{M}$ curcumin for $24 \mathrm{~h}$ and $30 \mathrm{mM}$ $\mathrm{HG}$ for $48 \mathrm{~h}$.

Assessment of cell viability. The cell viability was measured using a 3-(4,5-dimethylthiazol-2-yl)-2,5-diphenyltetrazolium bromide (MTT) assay. Briefly, $10 \mu \mathrm{l}$ MTT $(500 \mu \mathrm{g} / \mathrm{ml}$; Sigma-Aldrich) was added to the medium and the sample was incubated for $3 \mathrm{~h}$ at $37^{\circ} \mathrm{C}$ following treatment. Subsequently, the MTT solution was removed and $100 \mu \mathrm{l}$ dimethyl sulfoxide (Sigma-Aldrich) was added to the medium to dissolve the colored formazan crystals. The absorbance of each aliquot at $540 \mathrm{~nm}$ was measured using a Sunrise microplate reader (Tecan Group Ltd., Männedorf, Switzerland). The cell viability was determined as the ratio of the signal between the treated and control cultures.

Western blot analysis. The NRK-52E cells were pelleted by centrifugation at $125 \mathrm{x} \mathrm{g}$ at $4^{\circ} \mathrm{C}$ for $10 \mathrm{~min}$ and then washed once with phosphate-buffered saline. The cells were then lysed using a mixture of radioimmunoprecipitation assay buffer (Sigma-Aldrich) and phenylmethylsulfonyl fluoride (1:100; Sigma-Aldrich), on ice for $30 \mathrm{~min}$ with vortexing at intervals. 




Figure 1. Effects of curcumin on cell viability of NRK-52E cells. Cells were pre-incubated with curcumin $(0-20 \mu \mathrm{M})$ for $24 \mathrm{~h}$. Following curcumin treatment, the medium was changed and cells were treated with $30 \mathrm{mM} \mathrm{HG}$ for $48 \mathrm{~h}$. Cell viability was analyzed using an MTT assay. Data are presented as the mean \pm standard error of the mean $(n=5) ;{ }^{* *} \mathrm{P}<0.01$, vs. HG. HG, high glucose.

The lysates were then centrifuged at $8,000 \mathrm{x}$ f for $5 \mathrm{~min}$ at $4^{\circ} \mathrm{C}$. The total protein concentration measurement was performed using the Bradford method (15). The protein samples were boiled for $5 \mathrm{~min}$ and $50 \mu \mathrm{g}$ total protein was loaded into the appropriate well for 10\% SDS-PAGE (Beyotime Biotechnology, Shanghai, China). The proteins on the gel were then transferred onto a polyvinylidene difluoride membrane (EMD Millipore, Temecula, CA, USA) using Bio-Rad apparatus (A101441, Bio-Rad Laboratories, Inc., Hercules, CA, USA) for $2 \mathrm{~h}$ at $4^{\circ} \mathrm{C}$ and $100 \mathrm{~V}$. The protein-bound membranes were blocked and washed in Tris-buffered saline (TBS)-Tween 20 (20\%; Sigma-Aldrich). The membranes were incubated overnight at $4^{\circ} \mathrm{C}$ with primary antibodies. The primary antibodies used in the present study were as follows: Goat polyclonal anti- $\alpha$-smooth muscle actin ( $\alpha$-SMA; 1:400; cat. no. sc-324317), mouse monoclonal anti-E-cadherin (1:400; cat. no. sc-52327), mouse monoclonal anti-Nrf2 (1:400; cat. no. sc-365949), mouse monoclonal anti-HO-1 (1:400; cat. no. sc-136961) and mouse monoclonal anti- $\beta$-actin (1:400; cat. no. sc-47778) (all Santa Cruz Biotechnology, Inc.). Following extensive washing in TBS-0.1\% Tween 20, the membranes were then incubated with horseradish peroxidase-conjugated secondary antibodies, including rabbit anti-goat IgG (1:400; cat. no. sc-2922; Santa Cruz Biotechnology, Inc.) and rabbit anti-mouse IgG (1:400; cat. no. sc-358920; Santa Cruz Biotechnology, Inc.) overnight at $4^{\circ} \mathrm{C}$. Subsequently, the membranes were visualized using an enhanced chemiluminescence kit (Walterson Biotechnology Inc., Beijing, China) using the ChemiDoc ${ }^{\mathrm{TM}}$ XRS system with Quantity One software version 4.6 (Bio-Rad Laboratories, Inc.) and the G-BOX EF Chemi HR16 gel imaging system (Syngene, Frederick MD, USA). Following development, the band intensities were quantified using Image-Pro Plus 6.0 analysis software (Media Cybernetics, Inc., Rockville, MD, USA). The blots were repeated at least three times for each condition.

Transient transfection with Nrf2-small interfering RNA (siRNA). The cells were plated in six-well plates at a density of $2 \times 10^{5}$ cells/well in $2 \mathrm{ml}$ DMEM. The cells were transfected with Nrf2-specific siRNA (sense, 5'-GCACGGUGGAGUUCAUGATT-3' and antisense, 5'-UCAUUGAACUCCACCGUGCCT-3') (Santa Cruz Biotechnology, Inc). The target sequences of the Nrf2 siRNA and control Nrf2 siRNA were aligned against the GenBank database using the Basic Local Alignment Search Tool (http://blast.ncbi.nlm.nih.gov/Blast.cgi). Transient transfections were performed according to the manufacturer's instructions using Lipofectamine ${ }^{\circledR} 2000$ (Invitrogen Life Technologies, Carlsbad, CA, USA) to attenuate Nrf2 expression. All experiments were performed in six-well plates, with cells plated to reach $50-60 \%$ confluence on the day of transfection. The cells were incubated in growth medium with $10 \%$ fetal bovine serum for $24 \mathrm{~h}$ after transfection. The knockdown of Nrf2 was determined using western blot analysis.

Light microscopy. The cells (HG group) were cultured for $48 \mathrm{~h}$ with $30 \mathrm{mM} \mathrm{HG}$ at $37^{\circ} \mathrm{C}$. The cells (curcumin/HG group) were cultured with $10 \mu \mathrm{M}$ curcumin pretreatment for $24 \mathrm{~h}$ followed by $30 \mathrm{mM} \mathrm{HG}$ treatment for $48 \mathrm{~h}$ at $37^{\circ} \mathrm{C}$. The control cells were cultured for $48 \mathrm{~h}$ with $5 \mathrm{mM}$ glucose and $0 \mu \mathrm{M}$ curcumin at $37^{\circ} \mathrm{C}$. Subsequently, the cells were observed under a light microscope (Olympus CKX41-A32PH, Olympus, Tokyo, Japan).

Statistical analysis. Continuous variables are expressed as the mean \pm standard error of the mean. One-way analysis of variance was used to analyze the data. Tukey's multiple comparison test was used. $\mathrm{P}<0.05$ was considered to indicate a statistically significant difference.

\section{Results}

Curcumin rescues $H G$-induced inhibition of cell viability. The cell viability of NRK-52E cells under HG (30 mM) and curcumin $(0-20 \mu \mathrm{M})$ conditions were assessed. The results presented in Fig. 1 indicated that the HG condition significantly inhibited NRK-52E cell viability compared with that of the control group ( $5 \mathrm{mM}$ glucose and $0 \mu \mathrm{M}$ curcumin-treated cells). However, when the cells were treated with 10 or $20 \mu \mathrm{M}$ curcumin and HG, the viability of the was cells increased. Therefore, it was identified that curcumin had a protective effect on NRK-52E cells under HG conditions.

Curcumin decreases HG-induced EMT in NRK-52E cells. The HG-induced EMT of NRK-52E cells following curcumin treatment was assessed using light microscopy and western blotting. NRK-52E cells cultured in medium alone for $48 \mathrm{~h}$ exhibited typical cobblestone morphology under magnification. As shown in Fig. 2A, a typical epithelial cuboidal shape was observed in the NRK-52E cells cultured in DMEM (5 mmol/1 glucose), with the characteristic cobblestone morphology. Following treatment with $30 \mathrm{mM} \mathrm{HG}$, the cell morphology changed to a fibroblast-like shape, with reduced adherence, and the cells lost their apical-to-basal polarity. However, the cellular changes were more noticeable in the cells exposed to $30 \mathrm{mM}$ HG with $20 \mu \mathrm{M}$ curcumin for $48 \mathrm{~h}$. A previous study revealed that $\mathrm{HG}$ conditions were able to induce EMT in tubular epithelial cells (8). In fibroblasts, $\alpha$-SMA and vimentin proteins 
A



control



glucose $(30 \mathrm{mM})$



glucose $(30 \mathrm{mM})+$ curcumin

$\mathbf{B}$


Figure 2. Effects of curcumin on HG-induced epithelial-mesenchymal transition in the NRK-52E cells. (A) NRK-52E cells were treated with $30 \mathrm{mM}$ HG for $48 \mathrm{~h}$, with or without curcumin. Changes in cell morphology were observed using light microscopy (magnification, x200). (B) Representative western blots demonstrated that treatment with 10 or $20 \mu \mathrm{M}$ curcumin prevented HG-induced E-cadherin downregulation and $\alpha$-SMA upregulation following $48 \mathrm{~h}$ of treatment $(\mathrm{n}=6)$. All experiments were repeated three times and results are presented as the mean \pm standard error of the mean. $\left({ }^{* *} \mathrm{P}<0.01 \mathrm{vs}\right.$. control, ${ }^{\# \#} \mathrm{P}<0.01 \mathrm{vs}$. HG). HG, high glucose; $\alpha$-SMA, $\alpha$-smooth muscle actin; E-ca, E-cadherin.

A


B


Figure 3. Induction of Nrf2 protein expression in NRK-52E cells by curcumin. Nrf2 expression was analyzed using western blot analysis in cells treated with (A) various concentrations $(0,5,10,20 \mu \mathrm{M})$ of curcumin for $24 \mathrm{~h}$ or (B) $10 \mu \mathrm{M}$ curcumin for $0,3,6,12,24$ or $48 \mathrm{~h}$. Results are representative of three independent experiments. $\beta$-actin was used as a loading control. (" $\mathrm{P}<0.01$ vs. control). Nrf2, nuclear factor (erythroid-derived 2 )-like 2.

were detected; however, these proteins were not detected in the NRK-52E cells (41). E-cadherin, a $\mathrm{Ca}^{2+}$-dependent protein, is crucial in modulating renal epithelial polarity and a decrease in the expression of E-cadherin is considered to indicate
EMT (12). In order to detect HG-induced EMT, the levels of E-cadherin and $\alpha$-SMA were assessed using western blotting to analyze samples cultured under HG conditions (30 mM) with or without curcumin pretreatment. A decrease was detected 

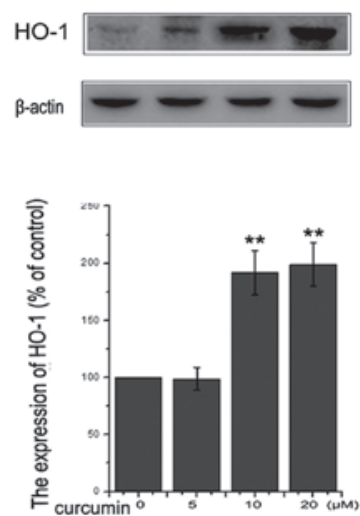

C


B


D



Figure 4. Induction of HO-1 protein expression in NRK-52E cells by curcumin. HO-1 expression was analyzed using western blotting following treatment of cells with (A) various concentrations $(0,5,10,20 \mu \mathrm{M})$ of curcumin for 24 h or (B) $10 \mu \mathrm{M}$ curcumin for $0,3,6,12,24$ or $48 \mathrm{~h}$. Results are representative of three independent experiments. $\beta$-actin was used as a loading control. ( ${ }^{* *} \mathrm{P}<0.01$ vs. control). (C and D) Cells were incubated with or without $50 \mu \mathrm{M}$ SnPP for $12 \mathrm{~h}$ and then administered $30 \mathrm{mM}$ glucose for $48 \mathrm{~h}$ with or without $10 \mu \mathrm{M}$ curcumin pretreatment for $24 \mathrm{~h}$. The expression of epithelial-mesenchymal transition proteins, E-cadherin and $\alpha$-SMA were assessed using western blot analysis. $\beta$-actin served as the loading control. Quantitative analysis was performed by measuring the fluorescence intensity relative to the control. Values are expressed as the mean \pm standard error of the mean ( $\mathrm{n}=10$ ). All results were obtained from three independent experiments. ( ${ }^{* *} \mathrm{P}<0.01$ vs. control). $\alpha$-SMA, $\alpha$-smooth muscle actin; SnPP, tin protoporphyrin; HO-1, heme oxygenase-1.

in the levels of E-cadherin, accompanied by an increase in $\alpha$-SMA expression (Fig. 2B), which suggested that these cells had undergone EMT in response to the HG conditions. This reduction in $\mathrm{E}$-cadherin protein expression in response to $\mathrm{HG}$ conditions was also accompanied by an increase in $\alpha$-SMA protein expression in our preliminary experiments, confirming that $\mathrm{HG}$ conditions promote EMT in NRK-52E cells. However, this HG-induced EMT was attenuated by pre-treating the NRK-52E cells with 10 or $20 \mu \mathrm{M}$ curcumin, demonstrated by the reduced upregulation of $\alpha$-SMA and the ameliorated expression of E-cadherin (Fig. 2B).

Curcumin increases Nrf2 expression in NRK-52E cells. Previous studies revealed that $\mathrm{Nrf} 2$ was able to regulate cytoprotective genes and cellular antioxidant proteins, as well as allow cells to adapt to stress induced by electrophiles and oxidants (42-44). To analyze the mechanism of action of curcumin on HG-induced EMT in the NRK-52E cells in the present study, the nuclear accumulation of Nrf2 protein in the curcumin-treated NRK-52E cells was examined. The cells were cultured with 0 , 5,10 or $20 \mu \mathrm{M}$ curcumin for $24 \mathrm{~h}$ or $10 \mu \mathrm{M}$ curcumin for 0,3 ,
$6,12,24$ or $48 \mathrm{~h}$ and the expression level of Nrf2 was detected using western blot analysis. The results shown in Fig. 3A and $\mathrm{B}$ indicated that the nuclear levels of Nrf2 were increased in a concentration and time-dependent manner when cultured with curcumin, compared with those of the control cells. It was therefore concluded that curcumin was capable of effectively inducing the expression of Nrf2 in NRK-52E cells.

Curcumin promotes expression of $\mathrm{HO}-1$ in NRK-52E cells. A number of studies have revealed that HO-1 is able to reduce apoptosis by inhibiting cellular oxidative stress $(20,45,46)$. In various types of cell, including glomerular or endothelial cells, the expression of HO-1 was demonstrated to be induced by curcumin in previous studies $(47,48)$. To elucidate the role of curcumin in renal tubular epithelial cells, HO-1 expression was assessed in NRK-52E cells cultured with curcumin. As indicated in Fig. 4A and B, curcumin was observed to upregulate $\mathrm{HO}-1$ protein expression in a dose- and time-dependent manner. Compared with the untreated controls, curcumin treatment led to a significant increase in the level of HO-1 protein expression. In order to determine whether $\mathrm{HO}-1$ exerted a cytoprotective 


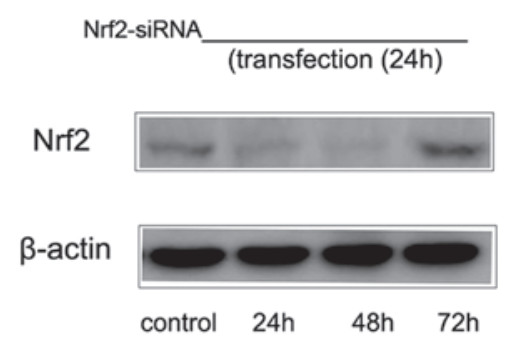

B



Nrf2-siRNA

(transfection $(24 \mathrm{~h})$


Figure 5. Nrf2 inhibits curcumin-induced HO-1 expression. (A) NRK-52E cells were transfected with Nrf2-siRNA and western blot analysis was performed with an antibody against Nrf2 was performed at variou time-points following transfection (24, 48 and $72 \mathrm{~h})$. Relative Nrf 2 expression levels were calculated and normalized to the loading control. Corresponding protein levels were assessed using densitometry and expressed in relative intensities. All results were obtained from three independent experiments. Values are expressed as the mean \pm standard error of the mean ( $\mathrm{n}=6$; ${ }^{* *} \mathrm{P}<0.01$, vs. control). (B) Cells were treated with curcumin $(0,5,10$ or $20 \mu \mathrm{M})$ for an additional $24 \mathrm{~h}$ with or without Nrf2-siRNA. Western blotting was performed with an antibody against HO-1. Relative HO-1 expression levels were calculated and normalized to the loading control. Corresponding protein levels were assessed using densitometry and were expressed in relative intensities. All results were obtained from three independent experiments. Values are expressed as the mean \pm standard error of the mean ( $\mathrm{n}=10 ;{ }^{* *} \mathrm{P}<0.01$, vs. control). HO-1, heme oxygenase-1; Nrf2, nuclear factor (erythroid-derived 2)-like 2; siRNA, small interfering RNA.

effect against the HG-induced EMT, $50 \mu \mathrm{M}$ SnPP, a known inhibitor of $\mathrm{HO}$, was utilized. The concentration of SnPP was determined as previously described (49). As shown in Fig. 4C and $\mathrm{D}, \mathrm{SnPP}$ treatment attenuated the protective effects of curcumin against HG-induced EMT in renal tubular epithelial cells. Notably, SnPP treatment alone did not affect cell viability in the present study (data not shown). In conclusion, curcumin was demonstrated to have a cytoprotective role, which is mediated through the induction of HO-1 expression.

siRNA knockdown of Nrf2 abrogates curcumin-induced HO-1 expression. In order to examine the role of $\mathrm{Nrf} 2$ in the upregulation of HO-1 expression, siRNA knockdown of the Nrf2 gene was used. The level of Nrf2 protein was detected using western blot analysis at various time-points following siRNA-Nrf2 transfection (Fig. 5A). siRNA-Nrf2 significantly reduced the HO-1 expression induced by curcumin treatment (Fig. 5B). In conclusion, the present findings supported the hypothesis that curcumin promotes the expression of $\mathrm{HO}-1$ through activation of Nrf2 in NRK-52E cells.

Anti-fibrotic effects of curcumin are mediated by activation of Nrf2 signaling. To determine whether curcumin protects cells against HG-induced EMT through the modulation of Nrf2 and HO-1 expression, the role of Nrf2 in EMT was investigated via knockdown of Nrf2. The cells were divided into six groups as follows: i) Control group; ii) siRNA group, subjected to Nrf2-siRNA transfection; iii) curcumin group, subjected to $10 \mu \mathrm{M}$ curcumin treatment for $24 \mathrm{~h}$; iv) $\mathrm{HG}$ group, 30 mM HG treatment; v) HG/curcumin group, $10 \mu \mathrm{M}$ curcumin pretreatment for $24 \mathrm{~h}$ followed by $30 \mathrm{mM} \mathrm{HG}$ treatment for $48 \mathrm{~h}$; vi) HG/curcumin/Nrf2-siRNA group, following transfection for $24 \mathrm{~h}$, cells were treated with $10 \mu \mathrm{M}$ curcumin for $24 \mathrm{~h}$ and $30 \mathrm{mM} \mathrm{HG}$ for $48 \mathrm{~h}$. The results revealed that $\mathrm{HG}$-induced EMT was partially prevented by curcumin pretreatment, which resulted in a decrease in the $\mathrm{HG}$-induced increase in $\alpha$-SMA expression and an increase in the expression of E-cadherin in NRK-52E cells (Fig. 6). In addition, Nrf2-siRNA alone did not induce EMT in the NRK-52E cells. However, knockdown of Nrf2 with siRNA inhibited the curcumin-induced anti-fibrotic effects (Fig. 6). These results suggested that curcumin protects NRK-52E cells from HG-induced EMT processes through activation of the Nrf2/antioxidant response signaling pathway and subsequent targeting of gene expression.

\section{Discussion}

Multiple studies have demonstrated that curcumin is capable of inhibiting fibrosis in certain chronic inflammatory diseases, including cystic fibrosis, liver fibrosis and myocardial fibrosis $(32,33)$. In the present study, the protective effect of curcumin on HG-induced EMT was analyzed in renal tubular epithelial cells. The results of the present study revealed that curcumin reduced HG-induced EMT in a dose- and time-dependent manner, as indicated by the detected decrease in the upregulation of $\alpha$-SMA and the increase in E-cadherin expression. The mechanism underlying this process may involve abrogation of HG-induced oxidative stress via activation of Nrf2 and HO-1 in NRK-52E cells. 
A



E-ca

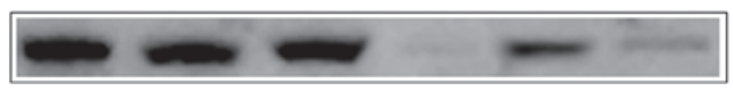

$\beta$-actin

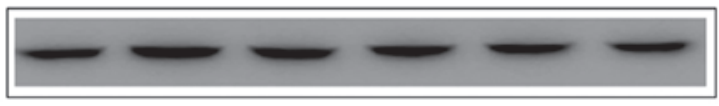

$$
\begin{aligned}
& \text { control Ni2-siRNA curcumin High glucose } \\
& \text { High glucoselcurcumin } \\
& \text { High glucoselcurcumin Nif2-siRNA }
\end{aligned}
$$

B

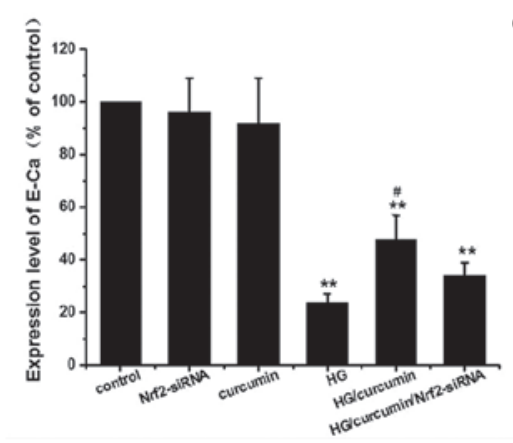

C



Figure 6. Curcumin-mediated activation of Nrf2 signaling protects cells against HG-induced EMT. Cells were incubated with or without Nrf2-siRNA prior to treatment with $30 \mathrm{mM} \mathrm{HG}$ for $48 \mathrm{~h}$ with or without $10 \mu \mathrm{M}$ curcumin pretreatment for $24 \mathrm{~h}$. (A) Western blotting was performed and relative expression of EMT proteins was calculated and normalized to the loading control. (B and C) Corresponding protein levels were assessed using densitometry and are expressed as relative intensities. Values are expressed as the mean \pm standard error of the mean $\left(\mathrm{n}=10 ;{ }^{* *} \mathrm{P}<0.01\right.$, vs. control, ${ }^{\#} \mathrm{P}<0.01, \mathrm{HG} / \mathrm{curcumin}$ vs. $\left.\mathrm{HG}\right)$. siRNA, small interfering RNA; EMT, epithelial-mesenchymal transition; HG, high glucose; Nrf2, nuclear factor (erythroid-derived 2)-like 2.

EMT in mature tubular epithelial cells of the kidney is currently considered to contribute to the renal accumulation of matrix proteins associated with DN and is closely associated with the progression of renal interstitial fibrosis $(7,50)$. In DN, EMT occurs in response to TGF- $\beta 1$ activation under HG conditions and contributes to the loss of tubular epithelial cells and the accumulation of interstitial fibroblasts, which are associated with a decline in renal excretory function $(11,13)$. Typical epithelial cell alterations, which are associated with EMT, include reorganization of the actin cytoskeleton, de novo acquisition of mesenchymal cytoskeletal markers and the downregulation of epithelial adhesion molecules $(51,52)$. To the best of our knowledge, the anti-fibrotic effects of curcumin have previously only been investigated in models of pulmonary or liver fibrosis, and curcumin was found to be associated with a reduction in the expression of inflammatory mediators, decreased expression of the profibrotic cytokine TGF- $\beta 1$ and a subsequent decrease in the accumulation of collagen $(32,33)$. Curcumin was also found to inhibit renal interstitial inflammation and fibrosis via inhibition of the NF- $\kappa \mathrm{B}$-dependent pathways in a UUO rat model of kidney fibrosis (35). A recent study revealed that curcumin inhibited TGF- $\beta 1$-induced EMT in renal tubular epithelial cells via the extracellular signal-regulated kinase-dependent and peroxisome proliferator-activated receptor $\gamma$-dependent pathways (53). In the present study, it was confirmed that HG-induced changes in EMT markers were more prominent than in the control and were accompanied by a decrease in the expression of epithelial marker E-cadherin and an increase in $\alpha$-SMA. Curcumin pretreatment may provide effective protection against HG-induced EMT, as evidenced by a decrease in the upregulation of $\alpha$-SMA and the amelioration of E-cadherin expression, which was associated with the transition from the epithelial to myofibroblastic phenotype in NRK-52E cells

A number of previous studies have confirmed that EMT in the tubular epithelial cells of patients with DN is generally regarded to be the result of hyperglycemia-induced oxidative stress; notably, antioxidants effectively reverse this induction of EMT in tubular epithelial cells $(6,13,16,54)$. Nrf2-mediated transcriptional responses have been found to be protective in a number of animal models of disease, including those of oxidative lung injury and fibrosis, asthma and brain ischemia-reperfusion $(55,56)$. The induction of kidney ischemia followed by reperfusion in wild-type mice was found to elevate Nrf2 levels and activate downstream target genes (57). By contrast, Nrf2 deficiency was demonstrated to enhance the susceptibility of cells to ischemic and nephrotoxic acute renal injury (58). Additionally, treatment of Nrf2 knockout mice with antioxidants, including $\mathrm{N}$-acetyl-cysteine or glutathione, is able to improve renal function (59). Furthermore, Nrf2 knockout mice with streptozotocin-induced diabetes were found to exhibit progressively increasing levels of nitric oxide metabolites in their urine, eventually developing renal injury (19). Curcumin is able to stimulate the dissociation of Nrf2 from Keap1, a 
cytosolic Nrf2 inhibitor, which leads to increased Nrf2 binding to the antioxidant response element in the promoters of target genes (33). Curcumin has also been demonstrated to be a potent inducer of Nrf2-associated antioxidant enzymes and an inhibitor of oxidant-induced $\mathrm{NF}-\kappa \mathrm{B}$ activation in lung epithelial cells (60). Similarly, in mouse alveolar macrophages in vitro and in the lungs in vivo, curcumin has been observed to upregulate Nrf2 target antioxidant gene expression (33). In addition, in the present study, it was also confirmed that curcumin induced Nrf2 activation in NRK-52E cells, which may represent the mechanism responsible for the protective effects of curcumin in cells subjected to HG-induced EMT.

To further examine the possible downstream mechanisms through which Nrf2 may elicit protection against HG-induced EMT, the expression of HO-1 was investigated in HG-treated cells transfected with siRNA-Nrf2. HO-1 is a rate-limiting enzyme involved in the degradation of heme to produce equimolar quantities of $\mathrm{CO}$, iron and biliverdin $(23,26)$. Growing evidence indicates that the HO-1 system is a regulator of renal vascular integrity and responses to oxidative stress (23). The induction of HO-1 expression by curcumin has been observed in several cell types, including human renal tubular cells and renal fibroblasts (14). A previous study revealed that curcumin exhibits an anti-fibrotic effect in a model of glomerular fibrosis, and curcumin treatment in vitro and in vivo may lead to the induction of HO-1 (47). The detailed mechanism through which curcumin induces HO-1 has been investigated in cultured cells (31). In human proximal tubular cells, curcumin-induced HO-1 expression was reduced by co-treatment with an $\mathrm{NF}-\kappa \mathrm{B}$ inhibitor, implicating this pathway in the modulation of HO-1 in this cell type. Other studies have indicated that, following curcumin treatment, there is an increase in HO-1 protein expression levels in kidney tissue and this mechanism is essential in the prevention of transplant-associated organ injury and rejection (61) Consistent with these results, the present data demonstrated that curcumin induced a marked increase in HO-1 levels and that transfection with siRNA-Nrf2 significantly attenuated this increase. Simultaneously, the $\mathrm{HG}$-induced reduction in E-cadherin and upregulation of $\alpha$-SMA were reversed by curcumin, whereas knockdown of Nrf2 with siRNA inhibited the curcumin-induced anti-fibrotic effects. The present results suggested that curcumin-mediated cell protection may occur via the activation of Nrf2 and subsequently the key target gene HO-1, thereby protecting NRK-52E cells from $\mathrm{HG}$-induced EMT processes.

In conclusion, the present study demonstrated that curcumin exhibited inhibition of HG-induced EMT in NRK-52E cells and that this effect was dependent on the activation of Nrf2 and subsequent HO-1 induction. The present data suggested that curcumin is a significant regulator of HG-induced EMT and may be beneficial in the treatment of DN. However, the underlying mechanisms require elucidation through further investigation.

\section{Acknowledgements}

The present study was supported by the National Grand Fundamental Research 973 Program of China (grant no. 2012CB722405), the Natural Science Foundation of China (grant nos. 81170561 and 81170775) and the Shenyang City Science and Technology program (grant no. F11-264-1-21).

\section{References}

1. Schena FP and Gesualdo L: Pathogenetic mechanisms of diabetic nephropathy. J Am Soc Nephrol 16 (Suppl 1): S30-S33, 2005.

2. Lapice E, Pinelli M, Riccardi G and Vaccaro O: Pro12Ala polymorphism in the PPARG gene contributes to the development of diabetic nephropathy in Chinese type 2 diabetic patients: comment on the study by Liu et al. Diabetes Care 33: e114; author reply e115, 2010 .

3. Ayodele OE, Alebiosu CO and Salako BL: Diabetic nephropathy - a review of the natural history, burden, risk factors and treatment. J Natl Med Assoc 96: 1445-1454, 2004.

4. Yeh $\mathrm{CH}$, Chang $\mathrm{CK}$, Cheng KC, Li YX, Zhang YW and Cheng JT: Role of bone morphogenetic proteins-7 (BMP-7) in the renal improvement effect of DangGui (Angelica sinensis) in type-1 diabetic rats. Evid Based Complement Alternat Med 2011: 796723, 2011.

5. Gilbert RE and Cooper ME: The tubulointerstitium in progressive diabetic kidney disease: more than an aftermath of glomerular injury? Kidney Int 56: 1627-1637, 1999.

6. Simonson MS: Phenotypic transitions and fibrosis in diabetic nephropathy. Kidney Int 71: 846-854, 2007.

7. Tang SC and Lai KN: The pathogenic role of the renal proximal tubular cell in diabetic nephropathy. Nephrol Dial Transplant 27: 3049-3056,2012.

8. Zeisberg M and Kalluri R: The role of epithelial-to-mesenchymal transition in renal fibrosis. J Mol Med Berl 82: 175-181, 2004.

9. Iwano M, Plieth D, Danoff TM, Xue C, Okada H and Neilson EG: Evidence that fibroblasts derive from epithelium during tissue fibrosis. J Clin Invest 110: 341-350, 2002.

10. Liu Y: New insights into epithelial-mesenchymal transition in kidney fibrosis. J Am Soc Nephrol 21: 212-222, 2010.

11. Burns WC, Twigg SM, Forbes JM, et al: Connective tissue growth factor plays an important role in advanced glycation end product-induced tubular epithelial-to-mesenchymal transition: implications for diabetic renal disease. J Am Soc Nephrol 17: 2484-2494, 2006

12. Lv ZM, Wang Q, Wan Q, et al: The role of the p38 MAPK signaling pathway in high glucose-induced epithelial-mesenchymal transition of cultured human renal tubular epithelial cells. PLoS One 6: e22806, 2011.

13. Lee YJ and Han HJ: Troglitazone ameliorates high glucose-induced EMT and dysfunction of SGLTs through PI3K/Akt, GSK-3 $\beta$, Snail1, and $\beta$-catenin in renal proximal tubule cells. Am J Physiol Renal Physiol 298: F1263-F1275, 2010.

14. Dogukan A, Sahin N, Tuzcu M, Juturu V, Orhan C, Onderci M, et al: The effects of chromium histidinate on mineral status of serum and tissue in fat-fed and streptozotocin-treated type II diabetic rats. Biol Trace Elem Res 131: 124-132,2009.

15. Simonian MH and Smith JA: Spectrophotometric and colorimetric determination of protein concentration. Curr Protoc Mol Biol 10: Unit 10.1A, 2006.

16. Kalluri R and Neilson EG: Epithelial-mesenchymal transition and its implications for fibrosis. J Clin Invest 112: 1776-1784, 2003.

17. Chen H, Zhang B, Yuan X, et al: Isoliquiritigenin-induced effects on Nrf2 mediated antioxidant defence in the HL-60 cell monocytic differentiation. Cell Biol Int 37: 1215-1224, 2013.

18. Jiang T, Huang Z, Lin Y, Zhang Z, Fang D and Zhang DD: The protective role of Nrf2 in streptozotocin-induced diabetic nephropathy. Diabetes 59: 850-860,2010.

19. Yoh K, Hirayama A, Ishizaki K, Yamada A, Takeuchi M, Yamagishi S, et al: Hyperglycemia induces oxidative and nitrosative stress and increases renal functional impairment in Nrf2-deficient mice. Genes Cells 13: 1159-1170,2008.

20. Abraham NG and Kappas A: Pharmacological and clinical aspects of heme oxygenase. Pharmacol Rev 60: 79-127, 2008.

21. Sikorski EM, Hock T, Hill-Kapturczak N and Agarwal A: The story so far: Molecular regulation of the heme oxygenase-1 gene in renal injury. Am J Physiol Renal Physiol 286: F425-F441, 2004.

22. Chan K, Han XD and Kan YW: An important function of Nrf2 in combating oxidative stress: detoxification of acetaminophen. Proc Natl Acad Sci USA 98: 4611-4616, 2001. 
23. Abraham NG, Cao J, Sacerdoti D, Li X and Drummond G: Heme oxygenase: the key to renal function regulation. Am J Physiol Renal Physiol 297: F1137-F1152, 2009.

24. Bolisetty S, Traylor A, Zarjou A, et al: Mitochondria-targeted heme oxygenase-1 decreases oxidative stress in renal epithelial cells. Am J Physiol Renal Physiol 305: F255-F264, 2013.

25. Quan S, Kaminski PM, Yang L, Morita T, Inaba M, Ikehara S, et al: Heme oxygenase-1 prevents superoxide anion-associated endothelial cell sloughing in diabetic rats. Biochem Biophys Res Commun 315: 509-516, 2004.

26. Kie JH, Kapturczak MH, Traylor A, Agarwal A and Hill-Kapturczak N: Heme oxygenase-1 deficiency promotes epithelial-mesenchymal transition and renal fibrosis. J Am Soc Nephrol 19: 1681-1691, 2008

27. Soetikno V, Sari FR, Lakshmanan AP, et al: Curcumin alleviates oxidative stress, inflammation, and renal fibrosis in remnant kidney through the Nrf2-keap1 pathway. Mol Nutr Food Res 57: $1649-1659,2013$.

28. Farhangkhoee $\mathrm{H}$, Khan ZA, Chen $\mathrm{S}$ and Chakrabarti S: Differential effects of curcumin on vasoactive factors in the diabetic rat heart. Nutr Metab (Lond) 3: 27, 2006.

29. Kowluru RA and Kanwar M: Effects of curcumin on retinal oxidative stress and inflammation in diabetes. Nutr Metab (Lond) 4: 8, 2007.

30. Maheshwari RK, Singh AK, Gaddipati J and Srimal RC: Multiple biological activities of curcumin: a short review. Life Sci 78 2081-2087, 2006

31. Sharma OP: Antioxidant activity of curcumin and related compounds. Biochem Pharmacol 25: 1811-1812, 1976.

32. Yao QY, Xu BL, Wang JY, et al: Inhibition by curcumin of multiple sites of the transforming growth factor-betal signalling pathway ameliorates the progression of liver fibrosis induced by carbon tetrachloride in rats. BMC Complement Altern Med 12: 156, 2012.

33. Suzuki M, Betsuyaku T, Ito Y, et al: Curcumin attenuates elastase- and cigarette smoke-induced pulmonary emphysema in mice. Am J Physiol Lung Cell Mol Physiol 296: L614-L623, 2009.

34. Gaedeke J, Noble NA and Border WA: Curcumin blocks multiple sites of the TGF-beta signaling cascade in renal cells. Kidney Int 66: 112-120, 2004.

35. Kuwabara N, Tamada S, Iwai $\mathrm{T}$, et al: Attenuation of renal fibrosis by curcumin in rat obstructive nephropathy. Urology 67 440-446, 2006.

36. Murugan P and Pari L: Influence of tetrahydrocurcumin on hepatic and renal functional markers and protein levels in experimental type 2 diabetic rats. Basic Clin Pharmacol Toxicol 101: 241-245, 2007.

37. Sharma S, Kulkarni SK and Chopra K: Curcumin, the active principle of turmeric (Curcuma longa), ameliorates diabetic nephropathy in rats. Clin Exp Pharmacol Physiol 33: 940-945, 2006

38. Bayrak O, Uz E, Bayrak R, Turgut F, Atmaca AF, Sahin S, et al: Curcumin protects against ischemia/reperfusion injury in rat kidneys. World J Urol 26: 285-291,2008.

39. Hill-Kapturczak N, Thamilselvan V, Liu F, Nick HS and Agarwal A: Mechanism of heme oxygenase-1 gene induction by curcumin in human renal proximal tubule cells. Am J Physiol Renal Physiol 281: F851-F859, 2001.

40. Gaedeke J, Noble NA and Border WA: Curcumin blocks fibrosis in anti-Thy 1 glomerulonephritis through up-regulation of heme oxygenase 1. Kidney Int 68: 2042-2049, 2005.

41. Zhang X, Zhao Y, Chu Q, Wang ZY, Li H and Chi ZH: Zinc modulates high glucose-induced apoptosis by suppressing oxidative stress in renal tubular epithelial cells. Biol Trace Elem Res 158: 259-267, 2014.

42. Holmström TH and Eriksson JE: Phosphorylation-based signaling in Fas receptor-mediated apoptosis. Crit Rev Immunol 20: 121-152,2000.

43. Nishiura T and Abe K: Alpha1-adrenergic receptor stimulation induces the expression of receptor activator of nuclear factor kappaB ligand gene via protein kinase $C$ and extracellular signal-regulated kinase pathways in MC3T3-E1 osteoblast-like cells. Arch Oral Biol 52: 778-785, 2007.
44. Zhang LY, Zhou YY, Chen F, et al: Taurine inhibits serum deprivation-induced osteoblast apoptosis via the taurine transporter/ERK signaling pathway. Braz J Med Biol Res 44: 618-623, 2011.

45. Chen YC, Chow JM, Lin CW, Wu CY and Shen SC Baicalein inhibition of oxidative-stress-induced apoptosis via modulation of ERKs activation and induction of $\mathrm{HO}-1$ gene expression in rat glioma cells C6. Toxicol Appl Pharmacol 216: 263-273, 2006

46. Parfenova H, Basuroy S, Bhattacharya S, Tcheranova D, Qu Y, Regan RF and Leffler CW: Glutamate induces oxidative stress and apoptosis in cerebral vascular endothelial cells: Contributions of HO-1 and HO-2 to cytoprotection. Am J Physiol Cell Physiol 290: C1399-C1410, 2006.

47. Yang C, ZhangX, Fan H and Liu Y: Curcumin upregulates transcription factor Nrf2, HO-1 expression and protects rat brains against focal ischemia. Brain Res 1282: 133-141, 2009.

48. Sahin K, Orhan C, Tuzcu Z, Tuzcu M and Sahin N: Curcumin ameliorates heat stress via inhibtion of oxidative stress and modulation of Nrf2/HO-1 pathway in quail. Food Chem Toxicol 50: 4035-4041, 2012

49. Uc A, Reszka KJ, Buettner GR and Stokes JB: Tin protoporphyrin induces intestinal chloride secretion by inducing light oxidation processes. Am J Physiol Cell Physiol 292: C1906-C1914, 2007.

50. Hills CE, Al-Rasheed N, Al-Rasheed N, Willars GB and Brunskill NJ: C-peptide reverses TGF-beta1-induced changes in renal proximal tubular cells: implications for treatment of diabetic nephropathy. Am J Physiol Renal Physiol 296: F614-F621, 2009.

51. Lan HY: Tubular epithelial-myofibroblast transdifferentiation mechanisms in proximal tubule cells. Curr Opin Nephrol Hypertens 12: 25-29, 2003.

52. Oldfield MD, Bach LA, Forbes JM, Nikolic-Paterson D, McRobert A, Thallas V, et al: Advanced glycation end products cause epithelial-myofibroblast transdifferentiation via the receptor for advanced glycation end products (RAGE). J Clin Invest 108: 1853-1863, 2001.

53. LiR, Wang Y,Liu Y, et al: Curcumin inhibits transforming growth factor- $\beta 1$-induced EMT via PPAR $\gamma$ pathway, not Smad pathway in renal tubular epithelial cells. PLoS One 8: e58848, 2013.

54. Kosugi T and Sato W: Midkine and the kidney: health and diseases. Nephrol Dial Transplant 27: 16-21, 2012.

55. Shih AY, Li P and Murphy TH: A small-molecule-inducible Nrf2-mediated antioxidant response provides effective prophylaxis against cerebral ischemia in vivo. J Neurosci 25: 10321-10335, 2005

56. Cho HY, Reddy SP, Yamamoto M and Kleeberger SR: The transcription factor NRF2 protects against pulmonary fibrosis. FASEB J 18: 1258-1260, 2004

57. Leonard MO, Kieran NE, Howell K, Burne MJ, Varadarajan R, Dhakshinamoorthy $\mathrm{S}$, et al: Reoxygenation-specific activation of the antioxidant transcription factor $\mathrm{Nrf} 2$ mediates cytoprotective gene expression in ischemia-reperfusion injury. FASEB J 20: 2624-2626, 2006.

58. Liu M, Grigoryev DN, Crow MT, Haas M, Yamamoto M, Reddy SP and Rabb H: Transcription factor Nrf2 is protective during ischemic and nephrotoxic acute kidney injury in mice. Kidney Int 76: 277-285, 2009.

59. Kanki K, Umemura T, Kitamura Y, et al: A possible role of nrf2 in prevention of renal oxidative damage by ferric nitrilotriacetate. Toxicol Pathol 36: 353-361, 2008.

60. Biswas SK, McClure D, Jimenez LA, Megson IL and Rahman I: Curcumin induces glutathione biosynthesis and inhibits NF-kappaB activation and interleukin- 8 release in alveolar epithelial cells: mechanism of free radical scavenging activity. Antioxid Redox Signal 7: 32-41, 2005.

61. Balogun E, Foresti R, Green CJ and Motterlini R: Changes in temperature modulate heme oxygenase- 1 induction by curcumin in renal epithelial cells. Biochem Biophys Res Commun 308: 950-955, 2003. 